Running head - Bone mineral density in treated celiac disease

\title{
No major reduction in Bone Mineral Density after long-term treatment of patients with Celiac Disease
}

Keywords: Celiac disease, Osteoporosis, Bone density

Petter Hære, MD, Sørlandet Hospital HF, Norway and Institute of Clinical Medicine, University of Oslo, Norway

Ole Høie, MD, PhD, Sørlandet Hospital HF, Norway

Knut E A Lundin, MD, PhD, Dept of Gastroenterology, Oslo University Hospital, Rikshospitalet, Norway and K.G. Jebsen Coeliac Disease Research Center, University of Oslo,Norway Glenn Haugeberg, MD, PhD, Sørlandet Hospital HF, Norway and NTNU, Norway

CORRESPONDING AUTHOR

Petter Hære

Sørlandet Sykehus HF, Dept. of Internal Medicine

PO Box 783, Stoa, 4809 Arendal

E-mail: petter.hare@sshf.no / Phone number: +47 91104251 


\section{INTRODUCTION}

Celiac disease (CD) is a disorder characterized by mucosal inflammation and villous atrophy (VA) in the small intestine. The disease has been shown to affect at least $1 \%$ of the European population[1]. The inflammatory reaction is triggered and maintained by the ingestion of gluten peptides found in common grains, such as wheat, barley and rye. The only causal treatment for CD is a gluten free diet (GFD) [2-4]. Patients may present with the classical symptoms associated with the disease, i.e. severe diarrhea, bloating and abdominal pain, but many patients also present with more atypical or lowgrade symptoms $[3,4]$. The wide spectrum of symptoms in CD causes some patients to go unrecognized for years, and most patients are diagnosed in adulthood. In addition to gastrointestinal symptoms, $\mathrm{CD}$ is associated with other manifestations such as nutrient deficiencies, dermatitis herpetiformis, endocrine disorders, malignancy and bone loss[5-11].

Osteoporosis is one of the consequences of $C D$, and studies have shown an increased prevalence of osteoporosis and low bone mineral density (BMD) in newly diagnosed CD patients[12-15]. The loss of bone mass looks to be at least partly reversible, as studies have shown an increase in BMD after treatment with a GFD $[12,14,16-19]$. Some of these studies also found that the observed increase in BMD is greatest in the first year after starting a GFD. Furthermore, studies on pediatric CD patients have shown that children can regain the lost bone mass and achieve a normal "peak bone mass" if they adhere to GFD[20-22]. Whether patients diagnosed in adulthood are able to regain a normal bone mass in the long run is still unclear. Primarily we aimed to explore BMD at femoral neck and lumbar spine in adult CD patients who had been treated with a GFD for at least two years, and to explore for associates with bone density. Secondarily we examined if osteoporosis treatment of CD patients were performed in compliance with guidelines and recommendations.

\section{METHODS:}

Study design 
This study is part of a broader study, aimed at describing several aspects of CD in a cohort of adult cohort of patients[23]. In this cross-sectional study, we present our findings on BMD and its associates. Clinical data were collected at patient visits to our outpatient clinic, and retrospective data was collected from the patients' hospital records.

\section{Patient population}

The patient recruitment has previously been described in detail[23]. In short, patients residing in Aust-Agder county (Southern Norway) and diagnosed with CD at least two years previously were identified through an extensive search in our pathology database. The search was based on pathology SnoMed codes corresponding to $C D$, mucosal atrophy and inflammation. All patients were then cross-referenced with their medical records to ensure that only patients with villous atrophy (VA) at the time of diagnosis were included. Patients without villous atrophy at the time of diagnosis were not eligible for inclusion. Pregnant women, patients with end-stage malignant disease and patients presumed not to be able to give an informed consent were also excluded from participation. Patients who had been diagnosed with $C D$ as children ( $<18$ years) were invited to participate in the general study, but they were not included in the statistical analyses of BMD and osteoporosis. In order to increase the external validity of our results, a second recruitment phase was performed. In this phase, patients who had failed to respond to our first request were invited to participate in a shortened version of the study limited to questionnaires only. Patient recruitment is shown in figure 1.

\section{Densitometry}

Patients underwent dual energy X-ray absorptiometry (DXA) scan of the lumbar spine L2-4 and femoral neck using a GE Healthcare (Chicago, IL, USA) Lunar Prodigy DXA machine. T-scores are based on the reference databases provided by the manufacturer (NHANES/USA, AP spine and femur 
American reference population, ages 20-40) and were calculated by the manufacturer software (GE

Lunar Prodigy enCORE). The Z-scores were calculated by the same software and are matched for age, gender, weight and ethnicity. Bilateral femoral neck scans were done in all patients where possible, and the results are reported as the average of both sides. The WHO cut point definitions for osteoporosis (T-score $\leq-2.5$ standard deviation (SD)), osteopenia (T-score $>-2.5$ SD and $<-1.0$ SD) and normal bone density (T-score $\geq-1.0 \mathrm{SD}$ ) were used[24]. The in-vitro long term coefficient of variance $(\mathrm{CV})$ for the spine phantom was $0.62 \%$. The in-vivo $\mathrm{CV}$ for the measurement procedure was 1.68\% for right femoral neck, 1.56\% for left femoral neck and 1.26\% for spine L2-4.

\section{FRAX risk score}

The 10-year risk of major osteoporotic fracture and hip fracture was calculated using the University of Sheffield Fracture Risk Assessment Tool (FRAX) for the Norwegian population[25]. The average femoral neck BMD $\left(\mathrm{g} / \mathrm{cm}^{2}\right)$ was used for risk calculation.

\section{Laboratory tests}

S-25-OH-vitamin-D, s-calcium (corrected for s-albumin) and s-PTH were measured in all patients. We defined vitamin D deficiency as s-25-OH-vitamin-D levels $<50 \mathrm{nmol} / \mathrm{l}$, regardless of PTH levels. Patients with s-25-OH-vitamin-D levels in the range of $50-75 \mathrm{nmol} / \mathrm{l}$ combined with an increased PTH level in the absence of hypercalcemia were also defined as having vitamin D deficiency and are reported separately. Patients without vitamin D deficiency, but who had an increased level of s-Ca in combination with an increase in PTH levels, were suspected of having primary hyperparathyroidism.

\section{Dietary assessment}

Adherence to GFD was assessed using the Celiac Disease Adherence Test (CDAT) developed by Leffler et al[26]. This system consists of 7 questions assessed on a 5-point Likert scale (1-5) resulting in a total sum of 7-35. Higher scores denote worse adherence to the diet. To note, the test does not 
measure gluten intake directly, but rather measures the risk of gluten exposure. Patients with CDAT scores $\leq 12$ were categorized as having "good adherence", and patients with scores $\geq 18$ were categorized as having "poor adherence".

\section{Symptom assessment}

Patient symptoms were registered using a modified 3-day Gastrointestinal Symptom Rating Scale, Irritable Bowel Syndrome version scoring system (GSRS-IBS)[27, 28]. The system evaluates 13 symptoms, each on a 7-point Likert scale (1-7). The scores can be aggregated into seven subcategories. Higher scores represent more intense symptoms.

\section{Compliance with osteoporosis treatment guidelines}

We examined to what extent our patients had used pharmacological treatment for osteoporosis or increased fracture risk in accordance with current guidelines. The treatment criteria of the National Osteoporosis Foundation (NOF) Clinician's Guide[29] were used for comparison. NOF recommends that the following men aged over 50 and postmenopausal women should be considered for treatment: Patients who either have A) experienced a hip or vertebral fracture, B) a T-score $\leq-2.5$, or C) a T-score between -1.0 and -2.5 combined with either a 10 year FRAX risk $\geq 3 \%$ for hip fractures or a risk $\geq 20 \%$ for a major osteoporosis-related fracture.

\section{Ethics}

All aspects of the study were pre-approved by the Norwegian Regional Committee for Medical and Health Research Ethics (REK, application number 2009/601). The study is performed in compliance with the Helsinki declaration.

\section{Statistics}


Data were analyzed using IBM SPSS Statistics v23 (IBM, Armonk, NY, USA) and the OpenEpi web or the chi-squared test (for categorical variables). $95 \%$ confidence intervals (CI) for observed proportions were calculated using the Wilson Score. Simple and multiple linear regression analyses were performed to examine for associates with BMD. Forward and backward multiple regression analyses were performed with an entry level of 0.05 and removal level of 0.10 . Binominal tests with Clopper-Pearson confidence intervals were used to compare observed proportions to the expected proportions in a normal population. A significance level of 0.05 was chosen.

\section{RESULTS:}

As previously reported we identified 285 patients who were eligible for study inclusion[23]. A total of 155 patients consented to participate in the first recruitment phase, and 151 of the patients consented to undergo DXA assessment. 143 of these patients had been diagnosed with CD as adults and were included in the statistical analyses (Figure 1). Patient characteristics are displayed in table 1. There was a significant age difference between the men and women in the study. Men were on average 6.8 years older than the women ( $\mathrm{Cl} 95 \%: 2.2-11.3$ years, $\mathrm{p}=0.004)$. The men were also diagnosed at an older age compared to the women, on average 5.9 years later (95\% $\mathrm{Cl}: 1.4-10.4$ years, $p=0.01)$. Men were significantly less likely to use calcium supplements $(p=0.04)$. There were no statistically significant gender differences in respect to treatment duration, Body Mass Index (BMI), adherence score (CDAT), total symptom score (GSRS-IBS), previous low energy fractures or smoking status. The mean duration of GFD was 9.3 years (median 8.0 years).

An additional 66 patients were recruited as part of the second phase of the study. These patients did not undergo DXA. 60 of the patients had been diagnosed as adults. These patients were on average 4.8 years younger than the group who underwent DXA $(95 \% \mathrm{Cl} 0.7-9.0$ years, $\mathrm{p}=0.02)$. In addition, they had been diagnosed at an earlier age, with a mean difference of 5.7 years $(95 \% \mathrm{Cl} 1.5-9.9$ years, 
$p=0.01)$. There was no statistically significant difference in treatment duration, adherence score or symptom score between these two groups.

\section{Densitometry data}

Mean BMD, T- and Z-score values for all patients, men, pre- and postmenopausal women separately are presented in table 2 . The prevalence of patients with normal bone density, osteopenia, osteoporosis and reduced bone density (defined as Z-score $\leq-1 \mathrm{SD}$ ) for all patients, men, pre-and postmenopausal women separately are presented in table 3 . When limiting analyses to only men and premenopausal women, the prevalence of osteoporosis at spine L2-4 and femoral neck was $2.1 \%$ (95\% $\mathrm{Cl} 0.6-7.4 \%)$ and $6.4 \%(95 \% \mathrm{Cl} 3.0-13.2 \%)$, while the prevalence of osteopenia at spine $\mathrm{L} 2-4$ and femoral neck was $19.1 \%(95 \% \mathrm{Cl} 12.5-28.3 \%)$ and $42.6 \%$ (95\% Cl 33.0-52.7\%). The prevalence of osteoporosis at any measurement site was $14.0 \%(95 \% \mathrm{Cl}$ 9.2-20.6\%) for all patients, $6.4 \%(95 \% \mathrm{Cl} 2.2-$ $17,2 \%)$ for men, $17.7 \%(95 \% \mathrm{Cl} 11.4-26.5 \%)$ for all women, $8.5 \%(95 \% \mathrm{Cl} 3.4-20.0 \%)$ for premenopausal women and $26.5 \%(95 \% \mathrm{Cl} 16.2-40.3 \%)$ for postmenopausal women, respectively.

For the whole sample population, mean Z-score at femoral neck was slightly lower than the DXA manufacturers reference population, with a mean difference of $-0.19(95 \% \mathrm{Cl}-0.34$ to $-0.04, p=0.012)$. The mean Z-score at spine L2-4 was not significantly different compared to the DXA reference population. We compared the observed prevalence of low Z-score $(\leq-1.0)$ to the expected prevalence in a reference population, which is by definition $15.9 \%$ (figure 2 ).

In our sample population, the observed prevalence of low Z-score at spine L2-4 was significantly higher than $15.9 \%(23.1 \%, 95 \% \mathrm{Cl}: 16.4-30.9 \%, \mathrm{p}=0.013)$. When excluding the postmenopausal women from the analyses, the prevalence of low Z-score at spine L2-4 did not differ significantly from the expected prevalence $(16.0 \%, 95 \% \mathrm{Cl}: 9.9-24.7)$. For the whole group, there was no significant difference between the observed and expected prevalence of low Z-score at the femoral neck 
(18.2\%, 95\%Cl: 12.2-25.5). Analyzing the postmenopausal group separately, there was a higher

prevalence of low Z-score at spine L2-4 when compared to the expected prevalence $(36.7 \%, 95 \% \mathrm{Cl}$ :

24.7-50.7, p<0.001), but not at the femoral neck $(20.4 \%, 95 \% \mathrm{Cl}: 11.5-33.6)$. There were no significant differences between the observed and expected prevalence of low Z-scores in premenopausal women or in men, neither at spine L2-4 or femoral neck. Premenopausal women had a significantly higher mean Z-score at spine L2-4 compared to the postmenopausal women, with a mean difference of 0.6 (95\% Cl: 0.1-1.2, $p=0.03)$, while there was no difference in the mean Z-score at the femoral neck.

We performed univariate linear regression analyses to examine clinical and laboratory parameters in relation to Z-scores at both spine L2-4 and femoral neck. Parameters analyzed were age at diagnosis and at study inclusion, duration of GFD, gender, postmenopausal status, body mass index, history of low energy fracture, CDAT score, GSRS-IBS score, smoking status, s-Ca, s-PTH, s-25-OH-vitamin-D, and calcium-, vitamin D and bisphosphatane treatment. In univariate analyses, CDAT score, GSRS-IBS total score and postmenopausal status were significantly related to Z-scores at spine L2-4. Forward and backward multiple linear regression analyses both yielded a model were only CDAT score and postmenopausal status added significantly to the prediction of Z-score at spine $L 2-4(R=0.124$, $\mathrm{p}=0.001$ ). No parameters were significantly associated with Z-score at femoral neck in univariate regression analyses.

\section{FRAX risk assessment}

For the whole sample population, the median FRAX risk score for major osteoporotic fracture and hip fracture were $5.4 \%$ (range 1.6-38.0\%) and 0.9\% (range 0-16\%), respectively. 11 women and two men (9.1\% of the patients) had a 10 -year risk for major osteoporotic fracture $\geq 20 \%$. 21 women and 11 men ( $22.4 \%$ of the patients) had a 10 -year risk for hip fracture $\geq 3 \%$. A total of 23 women and 11 men (23.8\%) had either an increased risk of a major osteoporotic fracture or hip fracture. 


\section{Laboratory results}

18 patients (12.6\%) had a s-25-OH-vitamin-D level < 50nmol/l. An additional eight patients (5.6\%) had levels between 50 and $75 \mathrm{nmol} / \mathrm{l}$ combined with an elevated PTH level in the absence of hypercalcemia, suggestive of vitamin D deficiency. There were no significant seasonal differences in mean 25-OH-vitamin-D levels across spring, summer, fall or winter. Two patients had elevated PTHlevels in combination with hypercalcemia, suggestive of primary hyperparathyroidism. Among the 26 patients with a vitamin D deficiency, seven patients (27\%) used vitamin D supplements. In comparison, 58 of the 117 patients (49.6\%) without vitamin D deficiency used vitamin D supplements $(p=0.036)$. We found no significant correlations between Z-scores and s-PTH, s-calcium or s-25-OHvitamin-D levels, neither at spine L2-4 or femoral neck.

\section{Adherence to the gluten free diet} According to CDAT scores, 68 patients (47.9\%) were classified as having good adherence while 14 patients (9.9\%) were classified as having poor adherence. 60 patients $(42.3 \%)$ had CDAT scores in the middle of these two extremes. The age of the patients predicted CDAT score, as younger patients tended to score higher $(\beta=-0.19, p=0.024)$. The mean spine $L 2-4 Z$-score of patients classified as having poor adherence $(-0.96)$ was significantly less than the mean Z-score of patients classified as having good adherence $(0.25)$ with a difference of $1.22(95 \% \mathrm{Cl}: 0.41-2.02, \mathrm{p}=0.003)$. There was no significant difference in mean femoral neck Z-score between patients with good and poor adherence.

\section{Treatment of osteoporosis and osteopenia}

There were a total of 33 men above fifty years of age and 49 postmenopausal women. According to the NOF clinician guideline, 11 of the men and 23 of the women fulfilled the criteria for pharmacological therapy. Of these, six (17.6\%) reported that they were or had been using bisphosphanate therapy for osteoporosis. $23(67.6 \%)$ patients reported that they had not. Five 
patients did not answer or did not know. 22 of the patients (64.7\%) used vitamin D supplements and $14(41.2 \%)$ used calcium supplements. In addition to the above patients, there were five premenopausal women who also fulfilled the criteria, although the guideline does not apply to them. One of these five women had been treated with bisphosphonates. There were no men under the age of fifty years who fulfilled the criteria.

\section{DISCUSSION}

In this study we have shown that adult, well treated CD patients in general have normal to nearnormal bone mineral density. Patients with signs of poor adherence to GFD had lower bone density, which emphasizes the importance of rigid diet adherence.

As reported in the review articles by Grace-Farfaglia[31] and Hjelle et al[11], prior studies show that low bone density is prevalent in the newly diagnosed patient with CD. Furthermore, there is an increase in bone density after treatment with a GFD, most pronounced in the first year after diagnosis. Our patient sample consists only of patients with a treatment duration of more than two years. We must therefore expect that the largest increase in BMD had taken place before enrollment in our study. This is indirectly supported by our data, as we do not find any significant correlation between treatment duration and BMD. Although we did not measure BMD at diagnosis, we hypothesize that patients with CD cannot expect a significant increase in BMD following the first two years of treatment with GFD. This may have consequences for patient follow-up.

A recent meta-analysis by Ganji et al [32] on the prevalence of osteoporosis and osteopenia in CD reported a pooled prevalence of osteoporosis at lumbar spine and hip at $16.3 \%$ and $13.3 \%$, respectively. The same study reported a pooled prevalence of osteopenia at lumbar spine and hip at $41.9 \%$ and $46.9 \%$, respectively. Our results show a lower observed prevalence of osteoporosis at both hip and spine L2-4, and lower observed prevalence of osteopenia at spine L2-4. It is important 
to note that only men and premenopausal women were included in the review study by Ganji et al.

As seen in our results, men and premenopausal women showed an even lower observed prevalence of osteoporosis and osteopenia compared to the postmenopausal women (except for a nonsignificant difference in the prevalence of femoral neck osteoporosis). The eight studies included in this meta-study reported a wide variety of treatment duration, where some studies also included patients close after diagnosis. This has the potential to overestimate the long term prevalence of osteoporosis, as we would expect some patients to increase in bone density in the time after diagnosis. One of the strengths of our study is that we have examined bone density in CD patients as late as, on average, nine years after diagnosis. By excluding patients with treatment duration less than two years, we believe our results more accurately reflect the long-term BMD in patients with CD.

There is great variation between studies regarding population sample, duration of disease, methods and how authors choose to report their results[33]. This makes it difficult to compare studies directly. The prevalence of osteopenia and osteoporosis, measured by T-scores, are affected by the population age, gender composition and menopausal status. As a patient naturally loses bone mineralization throughout his or her lifetime, T-scores will inevitably decrease. Although T-scores are the basis for diagnosing osteoporosis on the individual level, they are less suited for comparison between different study populations. Z-scores, on the other hand correct for age and gender. In unselected study populations, Z-scores would enable more accurate comparisons between different studies and against normative data. Our data shows very promising results for CD patients. Apart from an increase in the prevalence of low bone mass (Z-score $\leq-1.0)$ at spine $L 2-4$ in the postmenopausal group (36.8\%), the prevalence of low bone mass was not significantly different from what is expected levels in the normal population. Meyer et al[34] have previously reported Z-scores at forearm for several population-based cohorts in different parts of Norway. They found that the prevalence of low bone mass varied between geographical regions, ranging from 10.2-20.6\%. 
Although direct comparison between forearm-, femoral neck and spine measurements should be

performed with some caution, we note that the prevalence of low bone mass in our sample population falls within the range previously reported in the Norwegian normal population. Although osteoporosis is a justified concern in patients with newly diagnosed CD, our results indicate that bone density can normalize in the vast majority of patients. However, we cannot say to what degree these results translate into a fracture risk comparative to that of the normal population. It is important to note that our study population displays a high degree of mucosal healing[23]. Whether our data on BMD can be extrapolated to other populations with lesser degree of mucosal healing is uncertain.

More worrisome is the fact that only $17.6 \%$ of patients who should have been considered for pharmacological therapy according to the NOF guideline, had been using bisphosphonates. Two thirds of these patients were using vitamin D supplements but less than half used calcium supplements. In light of these findings, we are worried that patients with the highest risk of fracture do not get the recommended treatment. This may not necessarily be related to the care of patients with CD specifically, but rather reflect the general treatment threshold of low bone mass and osteoporosis in the Norwegian health care system. Up until recently, the cost of bisphosphonate treatment has only been reimbursed by our public health care system for postmenopausal women with established osteoporosis (T-score $<-2.5$ combined with a low energy fracture). Our prior reimbursement policies for bisphosphonate treatment may have prevented some patients, including patients with $C D$, from receiving such treatment. This finding may also reflect a general underawareness of osteoporosis by gastroenterologists and general physicians. We would suggest that all physicians practice a more aggressive case-finding in the celiac population in order to identify those with the highest risk of fractures.

Limitations of the study 
Although our patients were found to have near normal bone mass compared to normative data, the changes resulting from GFD. One could speculate that our patients did not have the same degree of osteopenia and osteoporosis at diagnosis as reported in other studies. However, we find this unlikely for two reasons: Firstly, the prevalence of osteoporosis and osteopenia in newly diagnosed patients have been reported consistently higher compared to controls in several studies, and there is no good reason to believe that our adult study population had a normal bone mass at diagnosis. Secondly, the incidence of hip fractures in Norway is one of the highest in the world[35], and we find it unlikely that our sample of Norwegian patients with CD would be better off than the normal population at the time of diagnosis. Furthermore, a hypothetical other study, where all patients had a DXA scan at the time of diagnosis could also have introduced a bias, since one could imagine that such patients would be more focused on bone health. Nevertheless, serial measurements would have strengthened the validity of our results. Due to the cross-sectional and retrospective study design, this was not possible.

The retrospective nature of our study design also made us unable to control for the effects of vitamin D supplementation, bisphosfanate exposure, weight gain etc. Although our results are promising, showing that the majority of patients have a normal bone mass, the presumed causal relationship between $C D$ treatment and bone mass normalization must be judged with caution.

The patients who underwent DXA measurements only accounted for $50 \%$ of the invited patients. One could therefore speculate whether our sample is representative of the population in our region. However, data from the second recruitment phase shows that the patients who initially declined to participate were younger and diagnosed at an earlier age, and there were no differences in treatment duration, adherence to GFD and symptom score. Therefore, we find it reasonable to believe that the bone density of patients who declined DXA are not worse than that of our examined 
patients. As we have discussed in our previous publication in the same patient cohort[23], we believe

The lack of a study control group limits the validity of our results. However, the reference database patients serve as a control group matched for age, gender, weight and ethnicity. Due to study methodology, we were only able to compare our results with this database and results from prior studies. There are geographical differences in BMD across different populations, even within countries, and we cannot rule out that the normal population in our region differs from that in the American reference database. Nevertheless, the previously published data on different Norwegian normal populations gives us a basis on which to compare our data.

\section{CONCLUSION}

Except for a small increase in the prevalence of low bone mass at spine L2-4 limited to the postmenopausal women, our patients, who had been treated with a gluten-free diet for at least two years and an average of 9.3 years, showed a normal bone mass when assessed by Z-score. Poor adherence was associated with lower spine L2-4 bone mass but not at the femoral neck. The duration of a GFD did not predict bone mass, which indicates that any potential increase in bone mass after diagnosis had taken place during the first two years. We hypothesize that most patients diagnosed with $C D$ as adults may regain or preserve a normal bone mass compared with persons of the same age, gender, weight and ethnicity. However, active case-finding of CD patients with the highest fracture risks may be warranted in order to identify those in need of pharmacological treatment.

\section{ACKNOWLEDGEMENTS}

We would like to thank study nurses Jane Rue and Margot Kvikshaug for their valuable help in data registration. We gratefully appreciate the expert technical assistance and help with the data 
collection of the osteoporosis nurses Lillann Krüger Hæstad, Hanne Vestaby, Tove Kjøstvedt. In addition, we would like to thank Tom B Schulz, MD, PhD, for his contribution to the planning of the study.

Funding for the study was primarily received from the South-Eastern Norway Health Authority Research fund. In addition, The Norwegian Celiac Society Research fund contributed financially in the planning phase of the study. 
1. Mustalahti K, Catassi C, Reunanen A, et al. The prevalence of celiac disease in Europe: results

2. . AGA Institute Medical Position Statement on the Diagnosis and Management of Celiac Disease. Gastroenterology. 2006;131:1977-1980.

3. Ludvigsson JF, Bai JC, Biagi F, et al. Diagnosis and management of adult coeliac disease: guidelines from the British Society of Gastroenterology. Gut. 2014;63:1210-1228.

4. Ludvigsson JF, Leffler DA, Bai JC, et al. The Oslo definitions for coeliac disease and related terms. Gut. 2013;62:43-52.

5. Wierdsma NJ, van Bokhorst-de van der Schueren MA, Berkenpas M, et al. Vitamin and mineral deficiencies are highly prevalent in newly diagnosed celiac disease patients. Nutrients. 2013;5:3975-3992.

6. Hovdenak N. [Associated disorders in celiac disease]. Tidsskr Nor Laegeforen. 1986;106:21432145, 2156.

7. Collin P, Reunala T, Pukkala E, et al. Coeliac disease--associated disorders and survival. Gut. 1994;35:1215-1218.

8. West J, Logan RF, Smith CJ, et al. Malignancy and mortality in people with coeliac disease: population based cohort study. BMJ. 2004;329:716-719.

9. Cosnes J, Cellier C, Viola S, et al. Incidence of autoimmune diseases in celiac disease: protective effect of the gluten-free diet. Clin Gastroenterol Hepatol. 2008;6:753-758.

10. Lundin KE and Wijmenga C. Coeliac disease and autoimmune disease-genetic overlap and screening. Nat Rev Gastroenterol Hepatol. 2015;12:507-515.

11. Hjelle AM, Apalset E, Mielnik P, et al. Celiac disease and risk of fracture in adults--a review. Osteoporos Int. 2014;25:1667-1676.

12. McFarlane XA, Bhalla AK and Robertson DA. Effect of a gluten free diet on osteopenia in adults with newly diagnosed coeliac disease. Gut. 1996;39:180-184.

13. Kemppainen $\mathrm{T}$, Kroger $\mathrm{H}$, Janatuinen $\mathrm{E}$, et al. Osteoporosis in adult patients with celiac disease. Bone. 1999;24:249-255.

14. Bai JC, Gonzalez D, Mautalen C, et al. Long-term effect of gluten restriction on bone mineral density of patients with coeliac disease. Aliment Pharmacol Ther. 1997;11:157-164.

15. Meyer D, Stavropolous S, Diamond B, et al. Osteoporosis in a north american adult population with celiac disease. Am J Gastroenterol. 2001;96:112-119.

16. Kemppainen $\mathrm{T}$, Kroger $\mathrm{H}$, Janatuinen $\mathrm{E}$, et al. Bone recovery after a gluten-free diet: a 5-year follow-up study. Bone. 1999;25:355-360.

17. Pantaleoni S, Luchino M, Adriani A, et al. Bone mineral density at diagnosis of celiac disease and after 1 year of gluten-free diet. ScientificWorldJournal. 2014;2014:173082.

18. Sategna-Guidetti C, Grosso SB, Grosso S, et al. The effects of 1-year gluten withdrawal on bone mass, bone metabolism and nutritional status in newly-diagnosed adult coeliac disease patients. Aliment Pharmacol Ther. 2000;14:35-43.

19. Zylberberg HM, Lebwohl B, RoyChoudhury A, et al. Predictors of improvement in bone mineral density after celiac disease diagnosis. Endocrine. 2018;59:311-318.

20. Mora S. Celiac disease in children: impact on bone health. Rev Endocr Metab Disord. 2008;9:123-130.

21. Mora S, Barera G, Beccio S, et al. Bone density and bone metabolism are normal after longterm gluten-free diet in young celiac patients. Am J Gastroenterol. 1999;94:398-403.

22. Molteni N, Caraceni MP, Bardella MT, et al. Bone mineral density in adult celiac patients and the effect of gluten-free diet from childhood. Am J Gastroenterol. 1990;85:51-53.

23. Haere $\mathrm{P}$, Hoie $\mathrm{O}$, Schulz $\mathrm{T}$, et al. Long-term mucosal recovery and healing in celiac disease is the rule - not the exception. Scand J Gastroenterol. 2016;51:1439-1446.

24. World Health Organization. Assessment of fracture risk and its application to screening for postmenopausal osteoporosis. Report of a WHO Study Group. World Health Organ Tech Rep Ser. 1994;843:1-129. 
25. The University of Sheffield. Online FRAX tool. site]. Available at http://www.shef.ac.uk/FRAX. Accessed 2016.

26. Leffler DA, Dennis M, Edwards George JB, et al. A simple validated gluten-free diet adherence survey for adults with celiac disease. Clin Gastroenterol Hepatol. 2009;7:530-536, 536 e531-532.

27. Wiklund IK, Fullerton S, Hawkey CJ, et al. An irritable bowel syndrome-specific symptom questionnaire: development and validation. Scand J Gastroenterol. 2003;38:947-954.

28. Brottveit M, Vandvik PO, Wojniusz S, et al. Absence of somatization in non-coeliac gluten sensitivity. Scand J Gastroenterol. 2012;47:770-777.

29. Cosman F, de Beur SJ, LeBoff MS, et al. Clinician's Guide to Prevention and Treatment of Osteoporosis. Osteoporos Int. 2014;25:2359-2381.

30. Dean AG, Sullivan KM and Soe MM. OpenEpi: Open Source Epidemiologic Statistics for Public Health. site]. Available at www. OpenEpi.com. Accessed 19th of september, 2017.

31. Grace-Farfaglia P. Bones of contention: bone mineral density recovery in celiac disease--a systematic review. Nutrients. 2015;7:3347-3369.

32. Ganji R, Moghbeli M, Sadeghi R, et al. Prevalence of osteoporosis and osteopenia in men and premenopausal women with celiac disease: a systematic review. Nutr J. 2019;18:9.

33. Larussa T, Suraci E, Nazionale I, et al. Bone mineralization in celiac disease. Gastroenterol Res Pract. 2012;2012:198025.

34. Meyer HE, Berntsen GK, Sogaard AJ, et al. Higher bone mineral density in rural compared with urban dwellers: the NOREPOS study. Am J Epidemiol. 2004;160:1039-1046.

35. Lofthus CM, Osnes EK, Falch JA, et al. Epidemiology of hip fractures in Oslo, Norway. Bone. 2001;29:413-418. 
Table 1.

\begin{tabular}{|c|c|c|c|c|}
\hline & \multicolumn{3}{|c|}{ DXA } & \multirow{2}{*}{$\begin{array}{l}\text { No DXA } \\
N=60\end{array}$} \\
\hline & $\begin{array}{l}\text { Men } \\
N=47\end{array}$ & $\begin{array}{l}\text { Women } \\
\mathrm{N}=96\end{array}$ & $\mathrm{~N}=143$ & \\
\hline Age (years, mean \pm SD) & $60.4 \pm 14.2$ & $53.6 \pm 12.1$ & $55.8 \pm 13.2$ & $51.0 \pm 15.0$ \\
\hline Age at diagnosis (years, mean \pm SD) & $50.5 \pm 14.1$ & $44.6 \pm 12.0$ & $46.6 \pm 13.0$ & $40.9 \pm 15.6$ \\
\hline Duration of GFD (years, mean \pm SD) & $9.8 \pm 5.3$ & $9.0 \pm 5.0$ & $9.3 \pm 5.1$ & $10.1 \pm 5.6$ \\
\hline Gender (female \%) & $0 \%$ & $100 \%$ & $67.1 \%$ & $67.2 \%$ \\
\hline Postmenopausal (\%) & NA & $51.0 \%$ & $34.3 \%$ & NA \\
\hline $\mathrm{BMI}\left(\mathrm{kg} / \mathrm{m}^{2}\right.$, mean $\left.\pm \mathrm{SD}\right)$ & $26.9 \pm 3.5$ & $25.6 \pm 5.3$ & $26.0 \pm 4.8$ & NA \\
\hline CDAT (mean score \pm SD) & $13.1 \pm 3.3$ & $13.3 \pm 3.0$ & $13.3 \pm 3.1$ & $14.0 \pm 4.1$ \\
\hline Current smokers (\%) & $10.6 \%$ & $13.5 \%$ & $12.6 \%$ & NA \\
\hline Previous smokers (\%) & $31.9 \%$ & $29.2 \%$ & $30.1 \%$ & NA \\
\hline Never smoked (\%) & $57.4 \%$ & $57.3 \%$ & $57.3 \%$ & NA \\
\hline GSRS-IBS (mean score \pm SD) & $26.1 \pm 10.6$ & $26.5 \pm 9.5$ & $26.4 \pm 9.8$ & $25.0 \pm 9.8$ \\
\hline Vitamin D supplements (\%) & $16(34.0 \%)$ & $49(51.0 \%)$ & $65(45.5 \%)$ & NA \\
\hline Calcium supplements (\%) & $8(17.0 \%)$ & $32(33.3 \%)$ & $40(28.0 \%)$ & NA \\
\hline $\begin{array}{l}\text { Previous or current bisphosphonate } \\
\text { treatment (\%) }\end{array}$ & $2(5.1 \%)$ & $7(9.3 \%)$ & $9(7.9 \%)$ & NA \\
\hline Previous low energy fracture (\%) & $5(10.6 \%)$ & $20(20.8 \%)$ & $25(17.5 \%)$ & NA \\
\hline
\end{tabular}

Table 1. Characteristics of celiac disease patients who consented to undergo DXA, and those who did not consent. DXA: Dual X-Ray Absorptiometry. SD: Standard Deviation. GFD: Gluten-Free Diet. BMI: Body Mass Index. CDAT: Celiac Disease Adherence Test. GSRS-IBS: Gastrointestinal Symptom Rating Scale, Irritable Bowel Syndrome version. 
Table 2

\begin{tabular}{|c|c|c|c|c|c|}
\hline & $\begin{array}{l}\text { Men } \\
n=47\end{array}$ & $\begin{array}{l}\text { All women } \\
n=96\end{array}$ & $\begin{array}{l}\text { Premenopausal women } \\
\qquad \mathrm{n}=47\end{array}$ & $\begin{array}{l}\text { Postmenopausal women } \\
\qquad \mathrm{n}=49\end{array}$ & $\begin{array}{c}\text { All } \\
n=143\end{array}$ \\
\hline \multicolumn{6}{|l|}{$\begin{array}{l}\text { Spine L2-4 } \\
\end{array}$} \\
\hline $\mathrm{BMD}\left(\mathrm{g} / \mathrm{cm}^{2}\right)$ & 1.239 (1.192 to 1.286$)$ & 1.143 (1.102 to 1.183$)$ & 1.245 (1.197 to 1.292 ) & 1.045 (0.991 to 1.098 ) & 1.174 (1.142 to 1.206$)$ \\
\hline T-score & $-0.01(-0.40$ to 0.39$)$ & $-0.48(-0.82$ to -0.14$)$ & 0.4 (0.0 to 0.8$)$ & $-1.3(-1.7$ to -0.9$)$ & $-0.33(-0.59$ to -0.06$)$ \\
\hline Z-score & $0.15(-0.24$ to 0.54$)$ & $0.11(-0.17$ to 0.38$)$ & 0.4 (0.1 to 0.8$)$ & $-0.2(-0.6$ to 0.2$)$ & $0.12(-0.10$ to 0.34$)$ \\
\hline \multicolumn{6}{|l|}{ Femoral neck } \\
\hline $\mathrm{BMD}\left(\mathrm{g} / \mathrm{cm}^{2}\right)$ & 0.942 (0.901 to 0.982$)$ & $0.892(0.865$ to 0.920$)$ & 0.962 (0.924 to 1.001$)$ & 0.825 (0.796 to 0.854$)$ & 0.909 (0.886 to 0.931$)$ \\
\hline T-score & $-0.99(-1.30$ to -0.67$)$ & $-1.21(-1.44$ to -0.99$)$ & $-0.6(-0.9$ to -0.3$)$ & $-1.8(-2.0$ to -1.5$)$ & $-1.14(-1.32$ to -0.96$)$ \\
\hline Z-score & $-0.19(-0-45$ to 0.07$)$ & $-0.19(-0.38$ to -0.01$)$ & $-0.1(-0.4$ to 0.2$)$ & $-0.3(-0.6$ to 0.0$)$ & $-0.19(-0.34$ to -0.04$)$ \\
\hline
\end{tabular}

Table 2. Bone mineral density (BMD), expressed as $\mathrm{g} / \mathrm{cm} 2, \mathrm{~T}$-score and Z-score at spine L2-4 and femoral neck in all 143 celiac disease patients and in patient subgroups. Data is presented as mean with $95 \%$ confidential intervals. 
Table 3

\begin{tabular}{|c|c|c|c|c|c|c|c|c|c|c|}
\hline & \multicolumn{2}{|r|}{$\begin{array}{l}\text { Men } \\
n=47\end{array}$} & \multicolumn{2}{|r|}{$\begin{array}{l}\text { All women } \\
n=96\end{array}$} & \multicolumn{2}{|c|}{$\begin{array}{l}\text { Premenopausal women } \\
\qquad n=47\end{array}$} & \multicolumn{2}{|c|}{$\begin{array}{l}\text { Postmenopausal women } \\
\qquad \mathrm{n}=49\end{array}$} & \multicolumn{2}{|r|}{$\begin{array}{c}\text { All } \\
n=143\end{array}$} \\
\hline & $\mathrm{n}$ & Prevalence $(95 \% \mathrm{Cl})$ & $n$ & Prevalence $(95 \% \mathrm{Cl})$ & $\mathrm{n}$ & Prevalence $(95 \% \mathrm{Cl})$ & $\mathrm{n}$ & Prevalence $(95 \% \mathrm{Cl})$ & $\mathrm{n}$ & Prevalence $(95 \% \mathrm{Cl})$ \\
\hline \multicolumn{11}{|l|}{ T-score L2-4 } \\
\hline$>-1.0 \mathrm{SD}$ & 34 & $72.3 \%(58.1-83.1)$ & 56 & $58.3 \%(48.3-67.7)$ & 40 & $85.1 \%(72.3-92.6)$ & 16 & $32.7 \%(21.2-46.6)$ & 90 & $62.9 \%(54.8-70.4)$ \\
\hline-1.0 to -2.5 SD & 13 & $27.7 \%$ (16.9-41.8) & 29 & $30.2 \%(21.9-40.0)$ & 5 & $10.6 \%(4.6-22.6)$ & 24 & $49.0 \%(35.6-62.5)$ & 42 & $29.4 \%(22.5-37.3)$ \\
\hline$\leq-2.5 \mathrm{SD}$ & 0 & $0 \%(0-7.6)$ & 11 & $11.5 \%(6.5-19.4)$ & 2 & $4.3 \%(1.2-14.3)$ & 9 & $18.4 \%(10.0-31.4)$ & 11 & $7.7 \%(4.3-13.3)$ \\
\hline \multicolumn{11}{|l|}{ T-score femoral neck } \\
\hline$>-1.0 \mathrm{SD}$ & 19 & $40.4 \%(27.6-54.7)$ & 39 & $40.6 \%(31.3-50.6)$ & 29 & $61.7 \%(47.4-74.2)$ & 10 & $20.4 \%(11.5-33.6)$ & 58 & $40.6 \%$ (32.9-48.8) \\
\hline-1.0 to -2.5 SD & 25 & $53.2 \%(39.2-66.7)$ & 46 & $47.9 \%(38.2-57.8)$ & 15 & $31.9 \%(20.4-46.2)$ & 31 & $63.3 \%(49.3-75.3)$ & 71 & $49.7 \%(41.6-57.8)$ \\
\hline$\leq-2.5 \mathrm{SD}$ & 3 & $6.4 \%(2.2-17.2)$ & 11 & $11.5 \%(6.5-19.4)$ & 3 & $6.4 \%(2.2-17.2)$ & 8 & $16.3 \%(8.5-29.0)$ & 14 & $9.8 \%(5.9-15.8)$ \\
\hline \multicolumn{11}{|l|}{ Z-score L2-4 } \\
\hline$>-1.0 \mathrm{SD}$ & 36 & $76.6 \%(62.8-86.4)$ & 74 & $77.1 \%(67.7-84.4)$ & 43 & 91.5\% (80.1-96.6) & 31 & $63.3 \%(49.3-75.3)$ & 110 & $76.9 \%(69.4-83.1)$ \\
\hline$\leq-1.0 \mathrm{SD}$ & 11 & $23.4 \%(13.6-37.2)$ & 22 & $22.9 \%(15.7-32.3)$ & 4 & $8.5 \%(3.4-20.0)$ & 18 & $36.7 \%(24.7-50.7)$ & 33 & $23.1 \%$ (16.9-30.6) \\
\hline \multicolumn{11}{|l|}{ Z-score femoral neck } \\
\hline$>-1.0 \mathrm{SD}$ & 38 & $80.9 \%(67.5-89.6)$ & 79 & $82.3 \%(73.5-88.7)$ & 40 & $85.1 \%(72.3-92.6)$ & 39 & $79.6 \%(66.4-88.5)$ & 117 & $81.8 \%(74.7-87.3)$ \\
\hline$\leq-1.0 \mathrm{SD}$ & 9 & $19.1 \%(10.4-32.5)$ & 17 & $17.7 \%(11.4-26.5)$ & 7 & $14.9 \%(7.4-27.7)$ & 10 & $20.4 \%(11.5-33.6)$ & 26 & $18.2 \%(12.7-25.3)$ \\
\hline
\end{tabular}

Table 3. Prevalence of celiac disease patients, for all and for subgroups, with normal bone density, osteopenia and osteoporosis and reduced bone density defined as Z-score $\leq-1$ SD at spine L2-4 and femoral neck. Data presented as numbers and percentage with $95 \%$ confidence intervals. 
Figure 1.

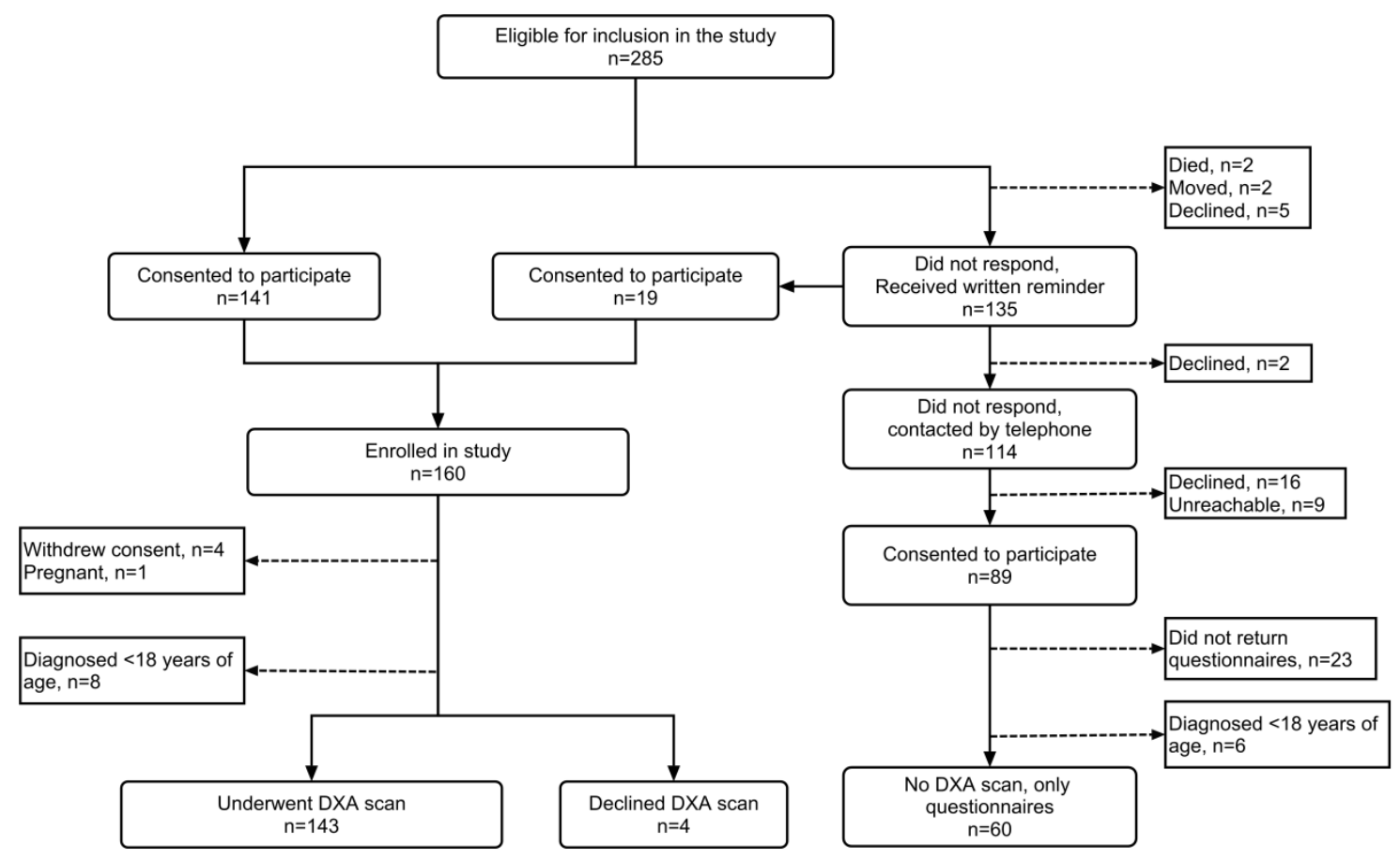

Figure 1. Flow-chart of the recruitment process. A total of 285 celiac disease patients were invited to participate, and 143 of these patients underwent densitometry. 
Figure 2.

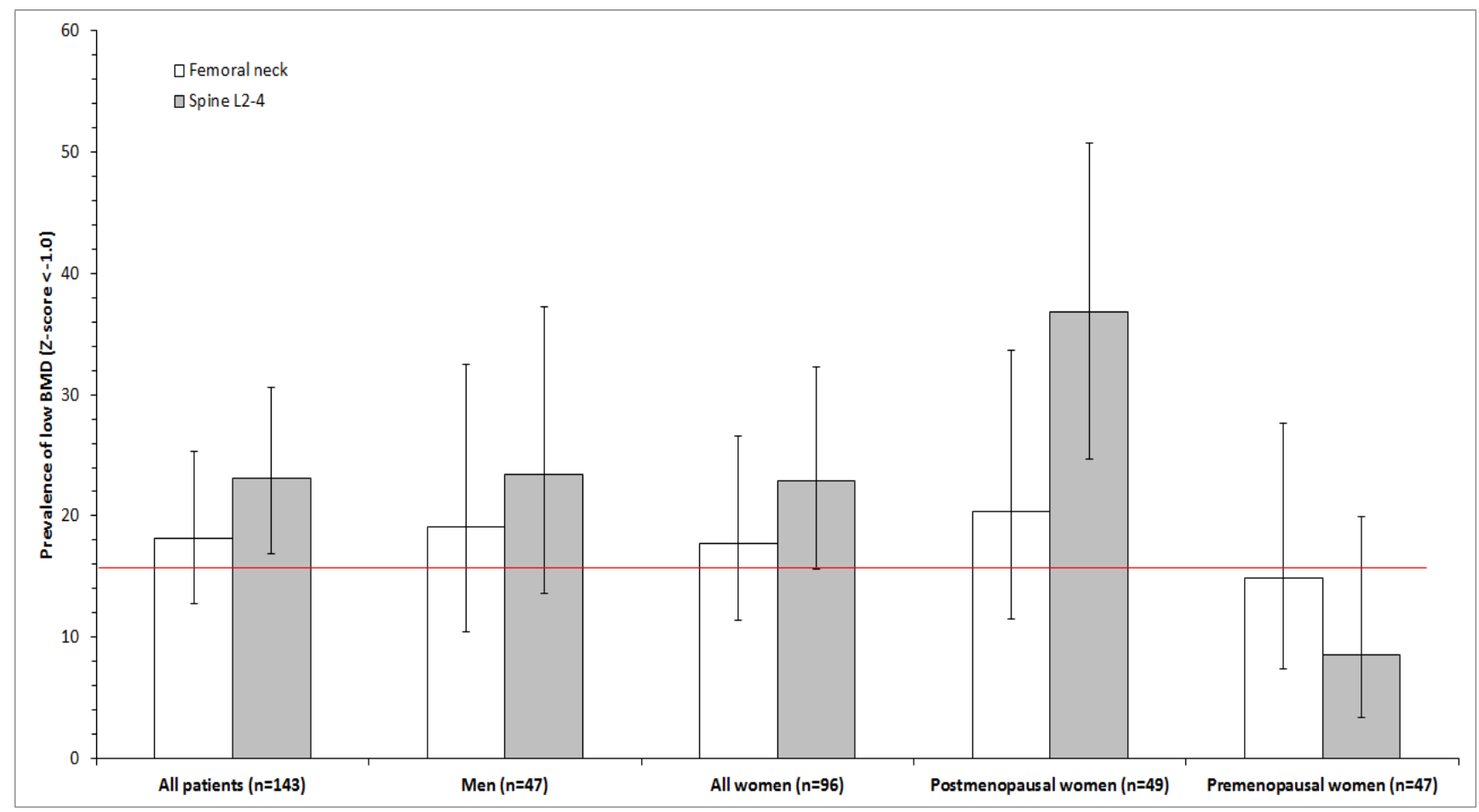

Figure 2. The prevalence (\%) of celiac disease patients who had a low BMD, defined as a Z-score <-

1.0. Error bars represent the $95 \%$ confidence interval of the prevalence estimate. The horizontal line represents the expected $15.9 \%$ prevalence of low BMD in a normal population. 


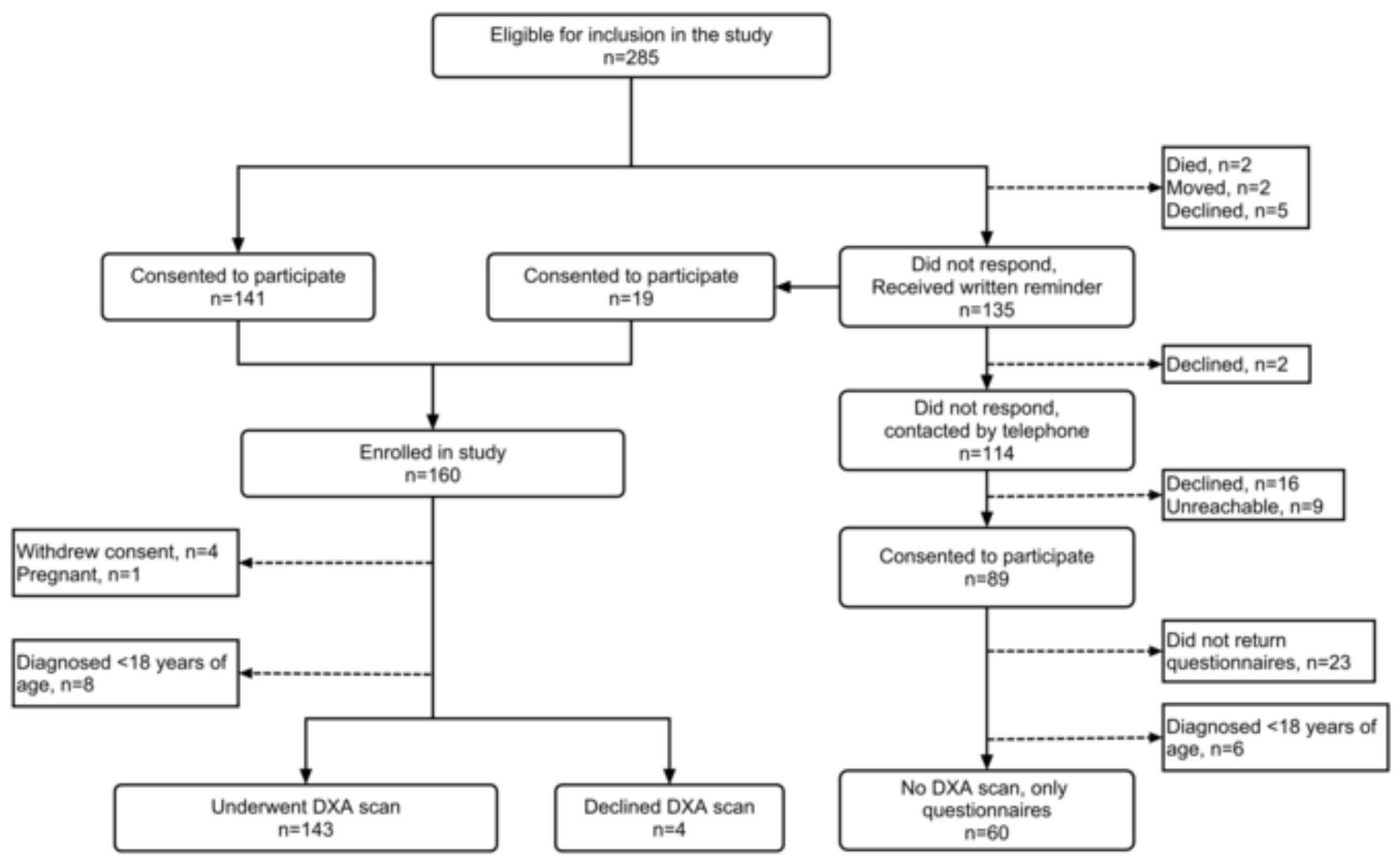


Figure 2 high resolution

Click here to download high resolution image

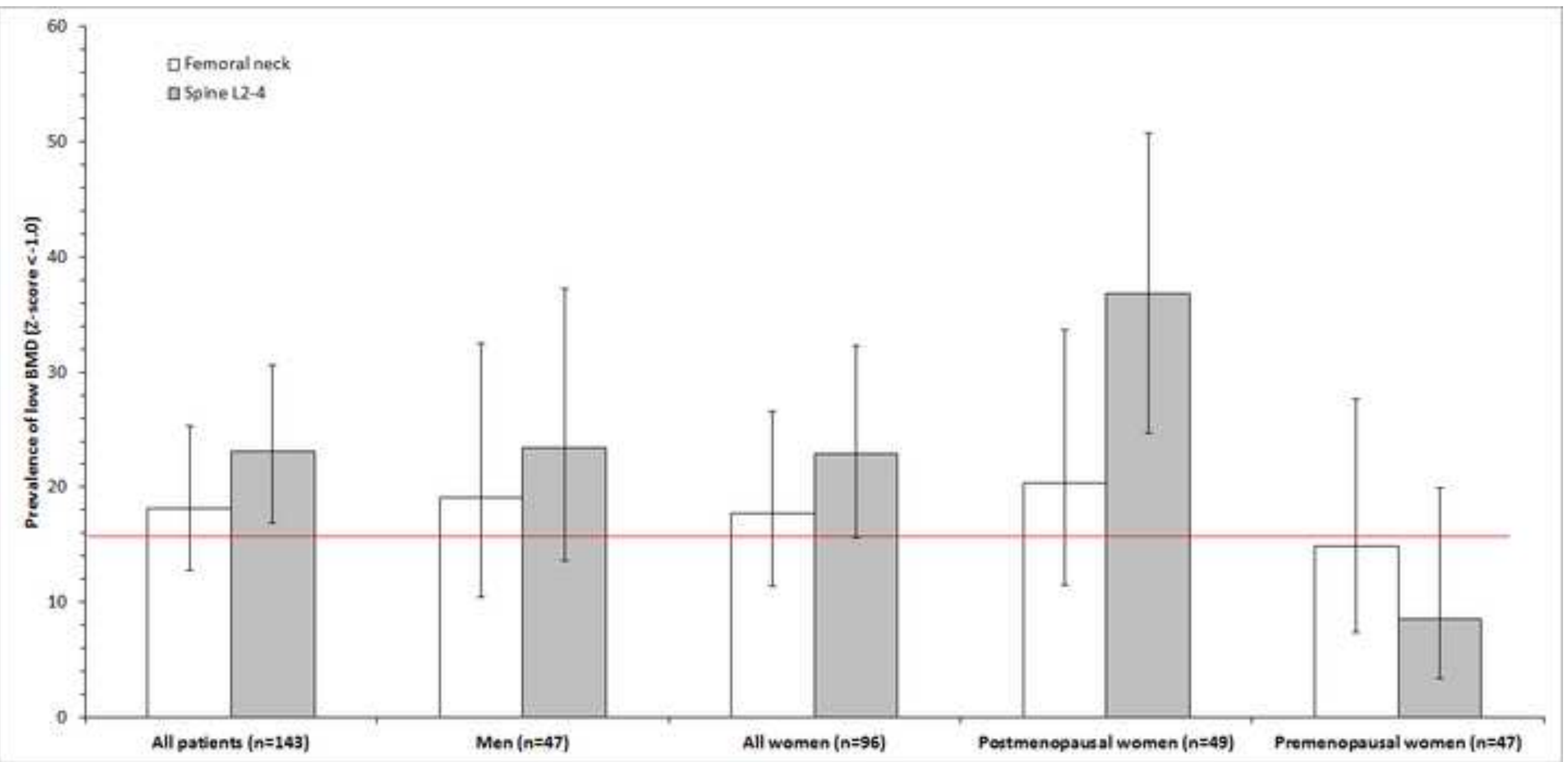




\section{CONFLICTS OF INTEREST}

The authors have no financial or personal conflicts of interest to declare.

\section{SOURCE OF FUNDING}

Funding for the study was primarily received from the South-Eastern Norway Health Authority Research fund. In addition, The Norwegian Celiac Society Research fund contributed financially in the planning phase of the study.

\section{COMPLIANCE WITH ICMJE AUTHORSHIP RECOMMENDATIONS}

All authors listed comply with the International Committee of Medical Journal Editors' (ICMJE) standards for authorship. 